\title{
PROTOTIPE PENGAWAS SISTEM PROTEKSI ARUS LEBIH ELEKTRONIK SECARA NIRKABEL
}

\author{
Arif Rahmadi Anwar \\ Fakultas Teknik, Program Studi Teknik Elektro \\ Universitas Widyagama Malang \\ Email: samsmined@gmail.com \\ Diky Siswanto \\ Fakultas Teknik, Program Studi Teknik Elektro \\ Universitas Widyagama Malang \\ Email: dsiswanto@widyagama.ac.id
}

\begin{abstract}
ABSTRAK
Relay arus lebih adalah peralatan yang sangat penting dalam sistem kelistrikan. Alat ini digunakan sebagai proteksi dari anomali atau gangguan yang dapat menimbulkan lonjakan arus dalam waktu singkat seperti ketika terjadi hubung singkat. Besarnya arus dapat merusak peralatan karena melebihi kemampuan hantar arus dari peralatan tersebut. Oleh sebab itu sistem proteksi menjadi peralatan yang wajib digunakan dalam sistem kelistrikan. Sistem proteksi ini terdiri dari beberapa peralatan seperti relay arus lebih, catu daya, baterai dan circuit breaker. Peralatan tersebut dirangkai menjadi satu sistem dengan menggunakan kabel yang rawan kendur, terlepas dan lain sebagainya yang masih belum terpantau kesiapannya setiap saat sehingga dapat berpotensi menyebabkan kegagalan sistem proteksi. Arduino uno merupakan perangkat mikrokontroler yang memiliki desain open source sehingga dapat diaplikasikan di semua peralatan elektronik. Alat ini dapat diterapkan dalam sistem proteksi untuk memantau tegangan catu daya dan baterai dengan menggunakan port analog input serta mengawasi rangkaian kabel trip coil dengan komponen optocoupler PC017 sebagai sensor input digital pada Arduino. Data yang diterima oleh Arduino uno akan dikirimkan ke online database dengan menggunakan wifi shield ESP8266, kemudian data tersebut akan ditampilkan pada aplikasi dalam ponsel Android. Dengan demikian, jika terdapat kerusakan pada salah satu peralatan tersebut maka petugas dapat segera melakukan perbaikan sebelum terjadi kegagalan sistem proteksi.
\end{abstract}

Kata kunci: proteksi; OCR; arduino; ESP8266; android.

\section{ABSTRACT}

Over current relay is very important equipment in power grid system. It's used as protection from anomalies or interference that cause a instantaneous current surge such as when a short circuit occurs. The amount of current can damage the equipment because it exceeds the current carrying capacity of the equipment. Therefore the protection system must be used in the power grid system. Protection system consist of several equipment such as over current relay, power supply, battery and circuit breaker. The equipment is assembled into one system using cables that are prone to loosening, detached etc that are still not monitored at all times. So they can potentially cause protection system failures. Arduino uno is a microcontroller device thas has an open source design, so that it can be applied to all electronic equipment. This tool can be applied in a protection system to monitor the power supply and battery voltage by using the analog input port and supervising the trip coil cable circuit with PC017 optocoupler as a digital input sensor on Arduino Uno. Data receiver by Arduino Uno will be sent to the online database using ESP8266 wifi shield, then the data will be displayed on the application on an Android phone. Thus, if there is damage at one of the equipment, the technician can immediately make some repairs before a protection system failure occurs

Keywords: Protection; OCR; arduinoa ESP8266; android.

\section{PENDAHULUAN}

Energi listrik telah menjadi kebutuhan primer yang sangat penting dan tidak tergantikan bagi seluruh lapisan masyarakat di era teknologi seperti sekarang ini. Namun selain sangat dibutuhkan, energi listrik juga dapat menimbulkan bahaya ketika terjadi gangguan pada sistem tersebut. Untuk mencegah dan meminimalisir bahaya yang ditimbulkan oleh energi listrik, maka diperlukan suatu alat pengaman yang disebut peralatan proteksi.

Saat ini masih banyak sistem kelistrikan yang menggunakan relai proteksi analog. Sayangya relai ini kerap kali mengalami kegagalan kerja karena kumparan pada relai dialiri arus listrik setiap saat, sehingga dapat menyebabkan penurunan kualitas inti besi. Pada akhirnya akan menyebabkan kesalahan respon relai proteksi serta berkurangnya 
keandalan dan keamanan sistem kelistrikan tersebut [1]. Selain itu, sistem proteksi terdiri dari relai proteksi dan circuit breaker serta peralatan pendukung seperti catu daya dan baterai. Peralatan tersebut dihubungkan menjadi sebuah sistem proteksi dengan menggunakan kabel yang rawan kendur, terlepas dan lain sebagainya yang masih belum terpantau kesiapannya setiap saat.

Beberapa peneliti telah merancang sistem monitoring pengawatan tripping coil dan suhu kontak pmt untuk mengantisipasi kegagalan trip [2]. Sistem ini bekerja dengan membunyikan sirine ketika terdapat kabel yang tidak terhubung sehingga mengharuskan petugas berada di dekat peralatan setiap saat. Berdasarkan riset tersebut, diketahui bahwa belum dikembangkan sistem pengawas sistem proteksi secara nirkabel yang dapat dipantau melalui ponsel Android.

Dalam penelitian ini akan dilakukan rancang bangun prototipe sistem pengaman arus lebih berbasis Arduino yang dilengkapi dengan rangkaian pengawas kesiapan sistem proteksi. Rangkaian ini memantau kondisi komponen sistem proteksi secara terus menerus. Hal ini dimaksudkan agar dapat meminimalisir gagal kerja yang disebabkan oleh ketidak-siapan salah satu perangkat dari sistem proteksi tersebut. Selain itu dapat digunakan untuk menggantikan relai proteksi analog yang diharapkan bisa meningkatkan keandalan sistem proteksi. Alat ini menggunakan pengolah data Arduino Uno ${ }^{\mathrm{TM}}$ dan wifi shield ESP8266 agar peralatan dapat dipantau secara wireless melalui ponsel Android. Dengan demikian maka petugas dapat segera melakukan perbaikan pada peralatan sebelum terjadinya kegagalan sistem proteksi.

\subsection{Rumusan Masalah}

Berdasarkan latar belakang di atas, dapat diperoleh permasalahan yang yang akan diselesaikan yaitu bagaimana merancang prototipe alat pengawas sistem proteksi arus lebih elektronik menggunakan Arduino yang dapat dimonitor secara nirkabel melalui ponsel android

\section{METODOLOGI PENELITIAN}

\subsection{Studi Pustaka}

\subsubsection{Over Current Relay}

Over current relay (OCR) adalah relai yang bekerja bila arus yang mengalir melebihi nilai yang telah ditentukan $\left(\mathrm{I}_{\text {setting }}\right)$ [3]. Terdapat tiga karakteristik relai arus lebih, yaitu:

a. Relai waktu seketika

b. Relai arus lebih waktu tertentu

c. Relai arus lebih waktu terbalik

\subsubsection{Mikrokontroler Arduino Uno}

Board Arduino Uno menggunakan ic mikrokontroler ATmega 328 dan memiliki 14 pin digital Input / Output yang diantaranya terdapat 6 pin untuk output PWM, 6 pin analog, $16 \mathrm{MHz}$ osilator kristal, koneksi USB, jack power, ICSP header, dan tombol reset[4]. Modul ini hadir dengan software IDE (Integrated Development Environment) yang merupakan media bagi pengguna untuk membuat program untuk modul arduino.

\subsubsection{Current Transformator}

Pada dasarnya, trafo arus digunakan untuk memperkecil besaran arus listrik (Ampere) pada sistem tenaga listrik menjadi besaran arus untuk sistem pengukuran dan proteksi. Prinsip kerja transformator arus sama dengan transformator daya.

\subsubsection{Circuit Breaker}

Kontaktor berfungsi sebagai penghubung dan pemutus sirkuit listrik dalam keadaan berbeban juga ketika terjadi short sirkuit (gangguan). Alat ini memiliki prinsip kerja yang sama dengan relai, namun memiliki kapasitas yang lebih besar dan diproduksi dalam banyak bentuk dan fitur yang beragam.

\subsubsection{Baterai 12V}

Baterai penyimpan energi listrik dalam bentuk reaksi kimia merupakan solusi penyimpanan energi listrik yang dapat disimpan dalam volume yang kecil dengan hasil output yang besar [5]. Energi listrik akan digunakan untuk mensuplai (menyediakan) listik ke suatu rangkaian listrik. 


\subsubsection{Relai DC $12 \mathrm{~V}$}

Relai adalah suatu piranti yang bekerja berdasarkan elektromagnetik untuk menggerakan sejumlah kontaktor yang tersusun atau sebuah saklar elektronis. Relai yang paling sederhana ialah relai elektromekanis yang memberikan pergerakan mekanis dari gaya tarik magnet saat kumparan dialiri energi listrik [6]

\subsubsection{Switching Mode Power Supply DC 12V 5A}

Power supply (catu daya) adalah suatu alat listrik yang digunakan untuk mengkonversi energi listrik agar energi listrik outputnya dapat digunakan oleh perangkat listrik ataupun elektronika lainnya[7].

\subsubsection{Modul Relai 5V}

Modul relai 5V merupakan suatu kumpulan relai yang telah dirakit sedemikian rupa sehingga telah dilengkapi dengan terminal. Modul ini dipasang rangkaian dumping untuk menghilangkan efek kejut (switching) dari kumparan relai.

\subsubsection{Modul Wifi Shield ESP8266}

Optocoupler adalah komponen elektronika yang berfungsi sebagai penghubung berdasarkan cahaya optik. Pada dasarnya Optocoupler terdiri dari 2 bagian utama yaitu Transmitter yang berfungsi sebagai pengirim cahaya optik dan Receiver yang berfungsi sebagai pendeteksi sumber cahaya [8].

\subsubsection{Sensor Optocoupler}

Optocoupler adalah komponen elektronika yang berfungsi sebagai penghubung berdasarkan cahaya optik. Pada dasarnya Optocoupler terdiri dari 2 bagian utama yaitu Transmitter yang berfungsi sebagai pengirim cahaya optik dan Receiver yang berfungsi sebagai pendeteksi sumber cahaya [8].

\subsection{Perancangan dan Pembuatan Alat}

Dalam skripsi ini, akan dilakukan rancang bangun sistem pengawas rangkaian proteksi arus lebih dengan kemampuan alat yang akan dibangun adalah sebagai berikut:

a. Dapat terhubung dengan database secara online melalui wifi shield

b. Dapat diakses secara realtime selama 24 jam oleh teknis.

c. Dapat memberikan notifikasi jika terdapat anomali atau kerusakan pada peralatan

\subsection{Cara Kerja Alat}

Catu daya akan menyediakan daya listik untuk sistem proteksi agar dapat bekerja. Saat peralatan bekerja dan sirkuit dalam kondisi tertutup, maka sensor arus akan mengukur besaran arus yang mengalir. Arduino uno akan mengolah data pengukuran arus tersebut. Jika nominalnya melebihi setting yang telah ditentukan, maka arduino uno akan mengirim sinyal trip kepada circuit breaker untuk memutus arus gangguan yang mengalir.

\subsection{Diagram Blok}

Berikut ini adalah blok diagram dari alat ini supaya lebih mudah dipahami. 


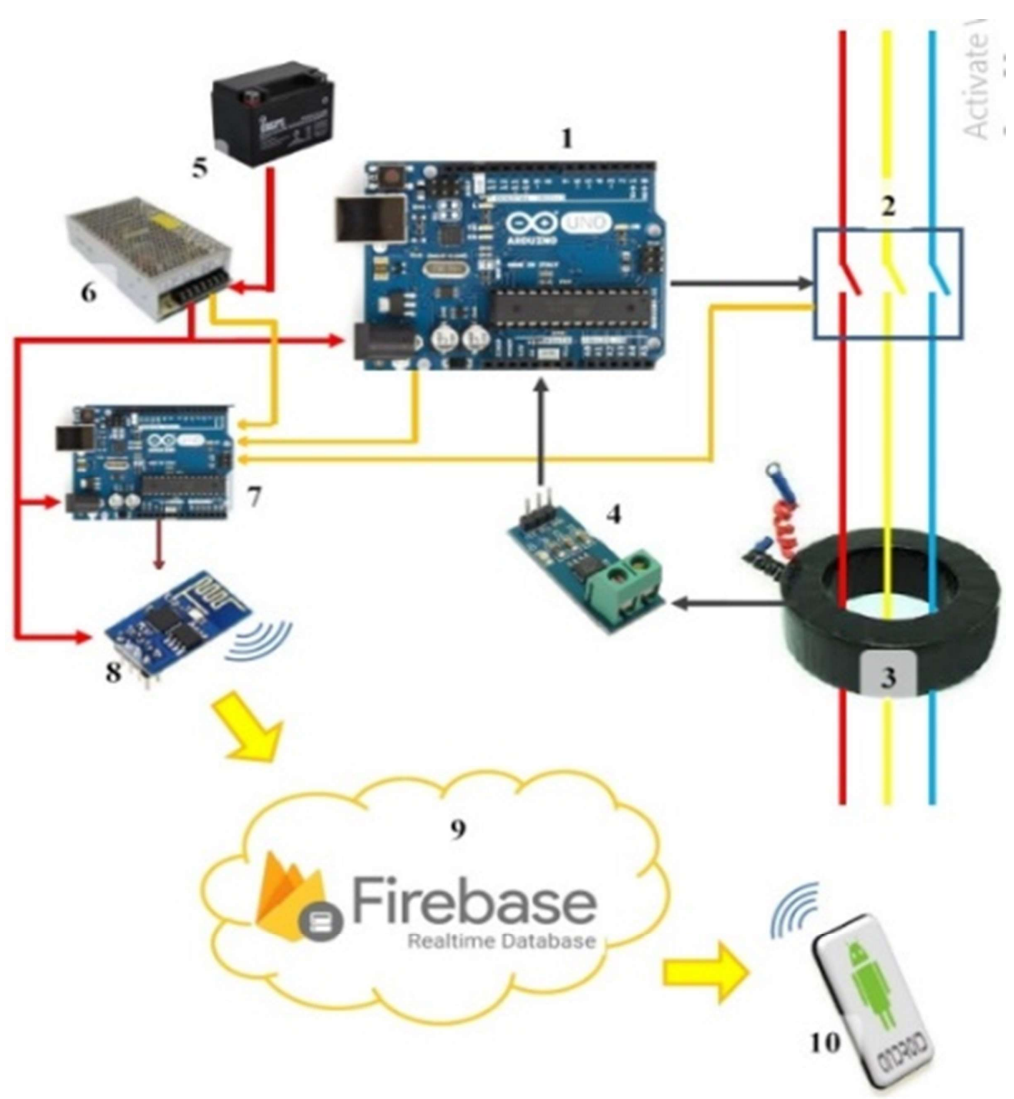

Gambar 1. Blok Diagram Alat

Berikut ini adalah keterangan serta penjelasan diagram blok di atas:

a. Arduino Uno sebagai pengolah data input dari sensor arus dan mengirimkan perintah trip kepada circuit breaker.

b. kontaktor yaitu sebagai saklar mekanik yang digunakan untuk memutus arus listrik saat terjadi gangguan.

c. Current transformer merupakan alat pengukur arus dengan skala tertentu sehingga nilai arus yang mengalir dapat diukur oleh Arduino.

d. Konverter, perangkat konversi dari pengukuran arus menjadi tegangan karena analog input Arduino berupa tegangan.

e. Baterai berfungsi untuk menyediakan energi listrik cadangan saat terjadi gangguan pada peralatan power supply.

f. Power supply berfungsi menyuplai daya listrik ke peralatan dan baterai

g. Arduino uno yang berfungsi untuk memantau kondisi sistem proteksi

h. Wifi shield merupakan perangkat yang akan mengirimkan data dari Arduino Uno ke realtime database.

i. Firebase merupakan penyedia jasa realtime database yang dapat digunakan sebagai media penghubung antara peralatan dengan aplikasi pada ponsel Android.

j. Smartphone Android digunakan untuk memantau kondisi sistem proteksi melalui aplikasi yang terhubung dengan realtime database. 
3.5 Flowchart Rangkaian pengawas Sistem Proteksi

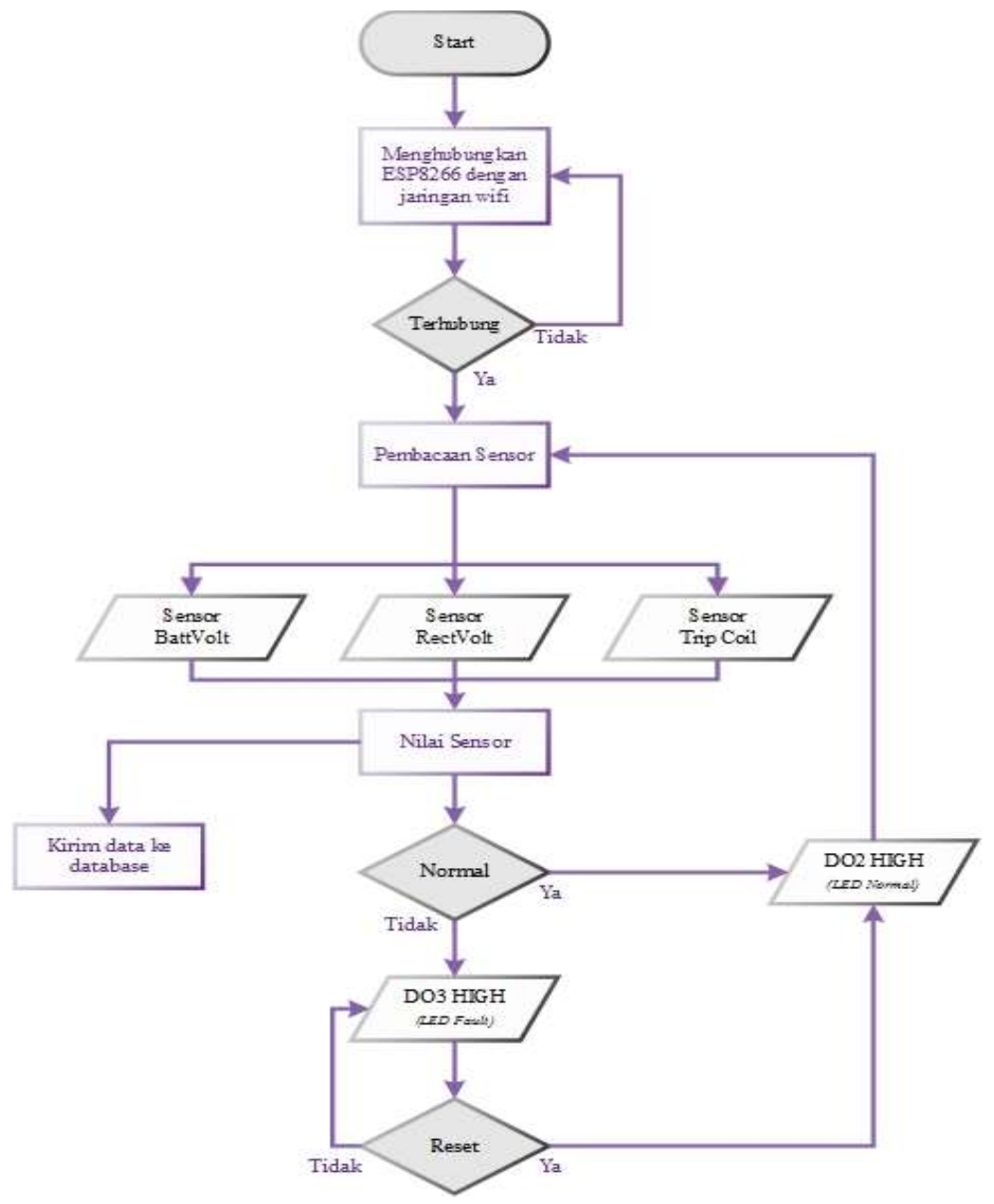

Gambar 2. Flowchart Sistem Pengawas 1

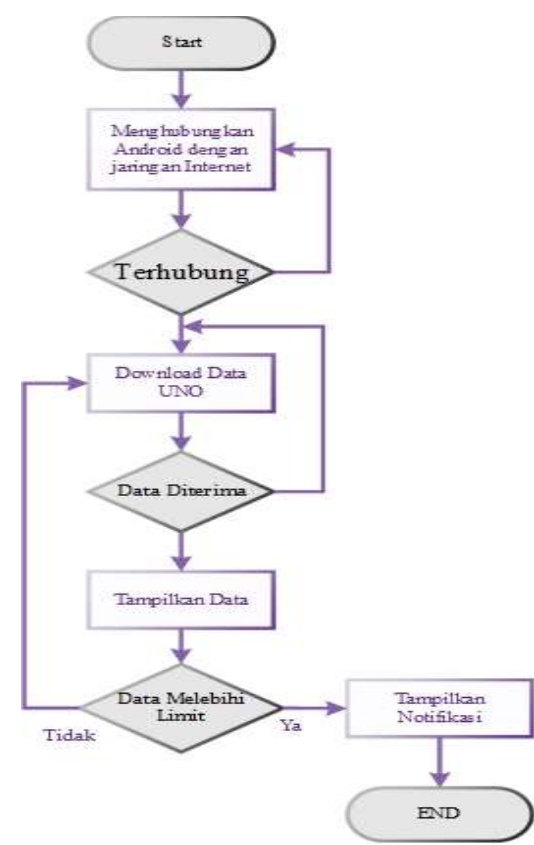

Gambar 3. Flowchart Sistem Pengawas Bagian 2 


\subsection{Flowchart Sistem Proteksi OCR}

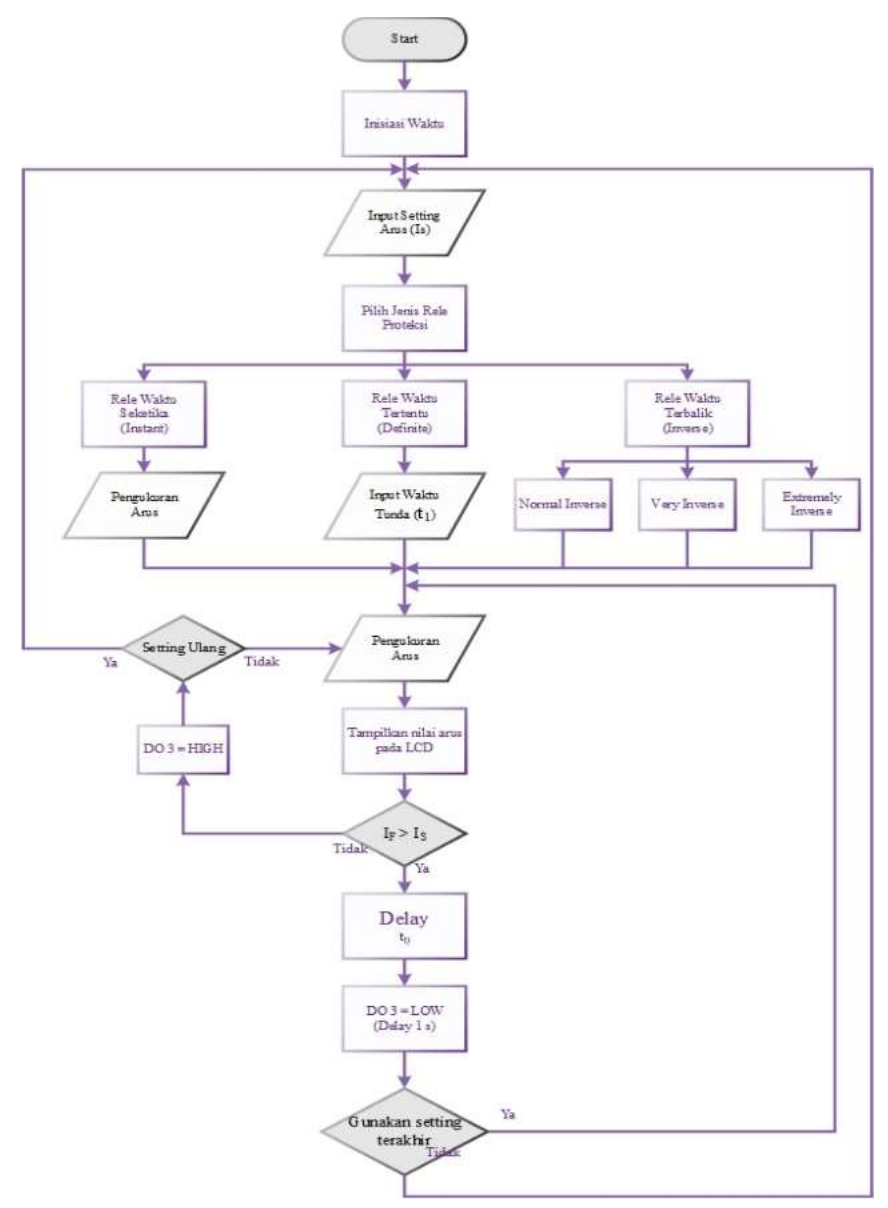

Gambar 4. Flow Chart Pengaman Arus Lebih

\subsection{Arduino IDE}

Perancangan kode yang akan digunakan pada mikrokontroler akan dijelaskan secara detail dalam diagram flowchart. Software yang digunakan untuk membuat kode program yaitu Arduino IDE dengan bahasa pemrograman berbasis JAVA.

\subsection{App Inventor}

Akan dibuat suatu aplikasi yang berfungsi untuk memantau kondisi kesiapan sistem proteksi. Aplikasi ini dibuat menggunakan aplikasi App Inventor

\section{HASIL DAN PEMBAHASAN}

Tujuan dilakukannya pengujian ini adalah untuk memperoleh data-data dari sistem yang telah dirancang dan dirakit menjadi satu. Data tersebut kemudian digunakan sebagai bahan analisa apakah terdapat ketidak sesuaian atau kerusakan alat tersebut sehingga alat dapat beroperasi dengan baik.

Pengujian dilakukan dengan menggunakan alat ukur yang telah terkalibrasi terhadap komponen secara terpisah terlebih dahulu untuk memastikan kinerja masing-masing komponen telah sesuai. Jika semua komponen dalam keadaan normal, maka pengujian berikutnya dilakukan ketika peralatan sudah digabungkan menjadi satu system 


\subsection{Pengujian Komponen}

\subsubsection{Pengujian Power Supply}

Pengujian power supply bertujuan agar alat ini dapat beroperasi dengan normal dan mampu menyuplai energi listrik ke peralatan. Dalam keadaan normal, power suppy menghasilan output tegangan DC $12 \mathrm{~V}$ dengan toleransi tegangan sebesar $\pm 10 \%$.

\section{Tabel 1. Data pengukuran tegangan power supply}

\begin{tabular}{cc}
\hline Tegangan Input & Tegangan Output \\
\hline $223 \mathrm{~V}$ & $12.50 \mathrm{~V}$ \\
\hline
\end{tabular}

Dari data yang telah diperoleh, dapat dilihat bahwa tegangan input catu daya sebesar $223 \mathrm{~V}$ dan tegangan output catu daya sebesar $12.5 \mathrm{~V}$ telah sesuai dengan spesifikasi yang tertera

\subsubsection{Pengujian Baterai}

Pengujian baterai bertujuan agar dapat menyediakan energi listrik saat terjadi gangguan pada input power supply $220 \mathrm{~V}$ AC. Tegangan baterai dalam keadaan penuh yaitu sebesar $12,60 \mathrm{~V}$, sedangkan ketika dalam keadaan kosong yaitu sebesar $10.85 \mathrm{~V}$

\subsubsection{Pengujian Arduino}

Pengujian mikrokontroler Arduino bertujuan agar alat ini dapat beroperasi dengan normal sesuai dengan alur kerjanya. Pengujian dilakukan dengan cara memastikan semua pin input dan output digital dapat bekerja dan input analog dapat menerima tegangan hasil pengukuran dari sensor.

\subsubsection{Pengujian Tegangan Arduino}

Pengujian tegangan kerja dilakukan agar dapat mengetahui kondisi rangkaian regulator dalam arduino. Karena tegangan kerja alat ini adalah $5 \mathrm{~V}$, sedangkan tegangan catu daya adalah $12 \mathrm{~V}$.

\subsubsection{Pengujian Analog Input}

Pengujian Analog Input dilakukan dengan cara memasukkan tegangan $0-5 \mathrm{~V}$ ke analog port pada arduino Uno. Input tegangan tersebut dapat diperoleh dari port $5 \mathrm{~V}$ arduino dan ditambahkan variabel resistor sehingga nilai tegangan input tersebut dapat diatur. Nilai tegangan tersebut berupa nilai analog yang kemudian dikonversikan oleh ADC menjadi data digital.

Tabel 2. Data pengukuran analog input

\begin{tabular}{ccc}
\hline $\begin{array}{c}\text { Tegangan } \\
\text { Input }\end{array}$ & $\begin{array}{c}\text { Nilai } \\
\text { Terukur } \\
\text { Serial Print }\end{array}$ & $\begin{array}{c}\text { Nilai } \\
\text { Perhitungan }\end{array}$ \\
\hline $0 \mathrm{~V}$ & 0 & 0 \\
\hline $1 \mathrm{~V}$ & 209 & 205 \\
\hline $2 \mathrm{~V}$ & 416 & 409 \\
\hline $3 \mathrm{~V}$ & 624 & 614 \\
\hline $4 \mathrm{~V}$ & 836 & 818 \\
\hline $5 \mathrm{~V}$ & 1023 & 1023 \\
\hline
\end{tabular}

Dari data pengujian tersebut, dapat dilihat bahwa terdapat selisih antara nilai yang terbaca pada Arduino dengan perhitungan. Hal ini dikarenakan peralatan yang digunakan untuk mengukur memiliki tingkat akurasi yang berbeda-beda. Perbedaan ini dapat ditoleransi dengan cara mengkalibrasi hasil pengukuran tersebut dalam program yang akan dibuat.

\subsubsection{Pengujian Port Digital}

Digital Input pada arduino hanya dapat membaca nilai High dan Low, yaitu berupa tegangan $0 \mathrm{~V}$ dan 5V. Pengujian dilakukan dengan cara memberikan tegangan pada port IO arduino. 
Tabel 3. Data pengukuran analog input

\begin{tabular}{cc}
\hline Tegangan Input & $\begin{array}{c}\text { Nilai Serial } \\
\text { Print }\end{array}$ \\
\hline $0 \mathrm{~V}$ & 0 \\
\hline $5 \mathrm{~V}$ & 1 \\
\hline
\end{tabular}

Dari data yang diperoleh, dapat dilihat bahwa pembacaan digital input pada Arduino telah sesuai dengan spesifikasi alat tersebut yaitu bernilai 1 dan 0 .

\subsubsection{Pengujian Circuit Breaker}

Pengujian circuit breaker bertujuan agar alat ini dapat melakukan pemutusan arus listrik ketika mendapatkan perintah dari Arduino Uno. Pengujian dilakukan dengan cara mennyambung dan memutus aliran listrik menuju kontaktor.

Tabel 4. Data pengujian circuit breaker

\begin{tabular}{cc}
\hline Input Tegangan & Kondisi Kontaktor \\
\hline $0 \mathrm{~V}$ & Terputus \\
\hline $220 \mathrm{~V}$ & Terhubung \\
\hline
\end{tabular}

Dari data di atas, dapat dilihat bahwa kontaktor bekerja dengan baik. Kontaktor dapat menghubungkan dan memutuskan rangkaian listrik sesuai dengan spesifikasi alat tersebut.

\subsubsection{Pengujian Aplikasi Android}

Pengujian dilakukan dengan cara membandingkan hasil pengukuran langsung pada alat dengan nilai yang tertampil pada aplikasi. Jika perbedaan nilai masih di bawah 1\%, maka aplikasi tersebut dalam keadaan normal.

Tabel 5. Data pengujian aplikasi android

\begin{tabular}{ccc}
\hline & $\begin{array}{c}\text { Nilai pada } \\
\text { database }\end{array}$ & $\begin{array}{c}\text { Nilai pada } \\
\text { aplikasi }\end{array}$ \\
\hline $\begin{array}{c}\text { Tegangan } \\
\text { baterai }\end{array}$ & $12.11 \mathrm{~V}$ & $12.11 \mathrm{~V}$ \\
\hline $\begin{array}{c}\text { Tegangan } \\
\text { Supply }\end{array}$ & $12.55 \mathrm{~V}$ & $12.55 \mathrm{~V}$ \\
\hline $\begin{array}{c}\text { Wiring } \\
\text { Trip Coil }\end{array}$ & 1 & Terhubung \\
\hline $\begin{array}{c}\text { Circuit } \\
\text { Breaker }\end{array}$ & 0 & OFF \\
\hline
\end{tabular}

Dari hasil pengujian di atas, dapat dilihat bahwa aplikasi telah berjalan sesuai dengan program yang telah dirancang sebelumnya. Data yang diperoleh secara pengukuran manual telah sesuai dengan data yang ditampilkan oleh aplikasi

\subsubsection{Pengujian Wifi Shield ESP8266}

Pengujian koneksi esp8266 dilakukan dengan melihat status perangkat melalui fitur serial monitoring pada arduino IDE. 


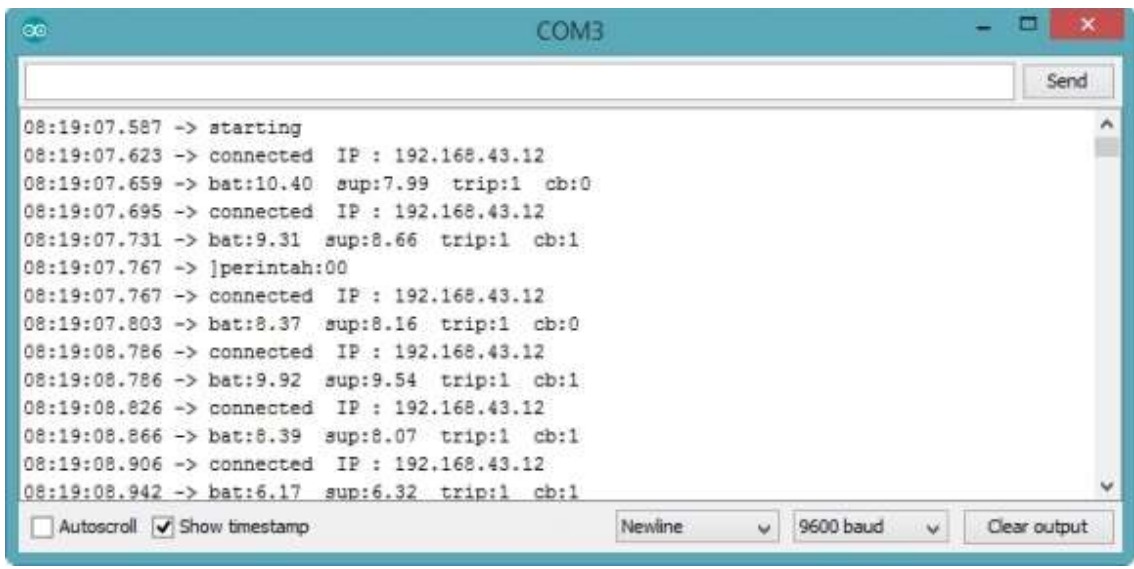

\section{Gambar 5. Tampilan koneksi dan IP perangkat ESP8266}

Dari data di atas, dapat dilihat bahwa Wifi shield dapat menghubungkan perangkat Arduino dengan jaringan internet sesuai dengan spesifikasi alat tersebut. Setelah wifi terhubung dengan arduino, selanjuatnya pengujian dilakukan dengan cara pengupload sketch yang berisikan alamat IP, kemudian melakukan Ping dari komputer dan melihat hasilnya. Ketika wifi shield dapat berkomunikasi dengan jaringan internet, maka akan ada reply dari ESP8266. Jika belum terhubung maka balasan ping berupa "Request Time Out".

\subsection{Pengujian Keseluruhan Sistem}

\subsubsection{Pengujian Over Current Relay}

Pengujian relai proteksi arus lebih dilakukan dengan cara pengukuran langsung dan membandingkan data yang diperoleh dengan perhitungan sesuai dengan jenis proteksi yang digunakan. Ada 3 jenis proteksi yang digunakan. Berikut adalah hasil pengujian masing-masing jenis proteksi:

Tabel 6. Tabel pengujian OCR Instant

\begin{tabular}{ccccc}
\hline $\begin{array}{c}\mathbf{I}_{\text {load }} \\
(\mathbf{A})\end{array}$ & $\begin{array}{c}\mathbf{I}_{\text {setting }} \\
(\mathbf{A})\end{array}$ & $\begin{array}{c}\mathbf{T}_{\text {Delay }} \\
\mathbf{( S )}\end{array}$ & $\begin{array}{c}\mathbf{T}_{\text {breaking }} \\
\mathbf{( S )}\end{array}$ & $\begin{array}{c}\text { Selisih } \\
\mathbf{( S )}\end{array}$ \\
\hline 1 & 1 & $\sim$ & $\sim$ & 0 \\
\hline 2 & 1 & 0 & 0.21 & 0.21 \\
\hline 3 & 1 & 0 & 0.23 & 0.23 \\
\hline 4 & 1 & 0 & 0.25 & 0.25 \\
\hline 5 & 1 & 0 & 0.19 & 0.19
\end{tabular}

Tabel 7. Tabel pengujian OCR Definite

\begin{tabular}{ccccc}
\hline $\begin{array}{c}\text { Iload } \\
(\mathbf{A})\end{array}$ & $\begin{array}{c}\mathbf{I}_{\text {setting }} \\
(\mathbf{A})\end{array}$ & $\begin{array}{c}\mathbf{T}_{\text {Delay }} \\
(\mathbf{S})\end{array}$ & $\begin{array}{c}\mathbf{T}_{\text {breaking }} \\
(\mathbf{S})\end{array}$ & $\begin{array}{c}\text { Selisih } \\
(\mathbf{S})\end{array}$ \\
\hline 1 & 1 & $\sim$ & $\sim$ & 0 \\
\hline 2 & 1 & 3 & 3.22 & 0.22 \\
\hline 3 & 1 & 3 & 3.19 & 0.19 \\
\hline 4 & 1 & 3 & 3.16 & 0.16 \\
\hline 5 & 1 & 3 & 3.17 & 0.17 \\
\hline
\end{tabular}

Tabel 8. Tabel pengujian OCR Inverse

\begin{tabular}{|c|c|c|c|c|}
\hline $\begin{array}{l}\text { Iload } \\
\text { (A) }\end{array}$ & $\begin{array}{c}\text { Isetting } \\
\text { (A) }\end{array}$ & $\begin{array}{c}\text { Tolay } \\
\text { (S) }\end{array}$ & $\begin{array}{c}\text { T breaking } \\
\text { (S) }\end{array}$ & $\begin{array}{c}\text { Selisih } \\
\text { (S) }\end{array}$ \\
\hline 1 & 1 & $\sim$ & $\bar{\sim}$ & 0 \\
\hline
\end{tabular}




\begin{tabular}{ccccc}
\hline $\begin{array}{c}\mathbf{I}_{\text {load }} \\
(\mathbf{A})\end{array}$ & $\begin{array}{c}\mathbf{I}_{\text {setting }} \\
(\mathbf{A})\end{array}$ & $\begin{array}{c}\mathbf{T}_{\text {Delay }} \\
(\mathbf{S})\end{array}$ & $\begin{array}{c}\mathbf{T}_{\text {breaking }} \\
(\mathbf{S})\end{array}$ & $\begin{array}{c}\text { Selisih } \\
(\mathbf{S})\end{array}$ \\
\hline 2 & 1 & 10.02 & 10.21 & 0.19 \\
\hline 3 & 1 & 6.30 & 6.47 & 0.17 \\
\hline 4 & 1 & 4.97 & 5.18 & 0.21 \\
\hline 5 & 1 & 4.27 & 4.43 & 0.16 \\
\hline 5 & 1 & 3.33 & 3.56 & 0.23 \\
\hline
\end{tabular}

Dari data yang telah diperoleh dalam pengujian di atas, dapat dilihat bahwa terdapat selisih antara waktu tunda hasil perhitungan dengan waktu tunda ketika percobaan dilaksanakan. Rata-rata selisih waktu yang tercatat sebesar 0.2035 detik. Selisih waktu tersebut masih memenuhi ketentuan dalan artikel IEEE 242 dimana yang diperlukan untuk rele mulai pick-up sampai kontak CB terbuka maksimal sebesar 0.350 detik [9].

\subsubsection{Sistem Pengawas Tegangan Baterai dan Power Supply}

Sistem pengawas tegangan ini bertugas untuk mengawasi nilai tegangan yang dihasilkan oleh power supply dan baterai. Pengukuran dilakukan dengan menggunakan rangkaian pembagi tegangan. Tegangan output memiliki nilai yang linier terhadap tegangan yang diukur. Tegangan Output akan diterima oleh arduino melalui port analog input yang tersedia.

Tabel 9. Hasil pengujian tegangan output dari catu daya

\begin{tabular}{cccc}
\hline $\begin{array}{c}\text { Tegangan } \\
\text { input } \\
\text { Divider }\end{array}$ & $\begin{array}{c}\text { Tegangan } \\
\text { Output } \\
\text { Divider }\end{array}$ & $\begin{array}{c}\text { Status } \\
\text { Pada } \\
\text { Aplikasi }\end{array}$ & $\begin{array}{c}\text { Tegangan } \\
\text { pada } \\
\text { aplikasi }\end{array}$ \\
\hline $10.0 \mathrm{~V}$ & $1.67 \mathrm{~V}$ & LOW & $10.0 \mathrm{~V}$ \\
\hline $10.5 \mathrm{~V}$ & $1.75 \mathrm{~V}$ & LOW & $10.5 \mathrm{~V}$ \\
\hline $11.0 \mathrm{~V}$ & $1.83 \mathrm{~V}$ & LOW & $11.0 \mathrm{~V}$ \\
\hline $11.5 \mathrm{~V}$ & $1.92 \mathrm{~V}$ & NORMAL & $11.5 \mathrm{~V}$ \\
\hline $12.0 \mathrm{~V}$ & $2.00 \mathrm{~V}$ & NORMAL & $12.0 \mathrm{~V}$ \\
\hline $12.5 \mathrm{~V}$ & $2.08 \mathrm{~V}$ & NORMAL & $12.5 \mathrm{~V}$ \\
\hline $13.0 \mathrm{~V}$ & $2.17 \mathrm{~V}$ & NORMAL & $13.0 \mathrm{~V}$ \\
\hline $13.5 \mathrm{~V}$ & $2.25 \mathrm{~V}$ & NORMAL & $13.5 \mathrm{~V}$ \\
\hline $14.0 \mathrm{~V}$ & $2.33 \mathrm{~V}$ & HIGH & $14.0 \mathrm{~V}$ \\
\hline $14.5 \mathrm{~V}$ & $2.42 \mathrm{~V}$ & HIGH & $14.5 \mathrm{~V}$ \\
\hline $15.0 \mathrm{~V}$ & $2.50 \mathrm{~V}$ & HIGH & $15.0 \mathrm{~V}$ \\
\hline
\end{tabular}

Dari tabel di atas dapat dilihat bahwa tanda status peringatan telah berjalan sesuai dengan rancangan aplikasi yang telah dibuat. Ketika tegangangan baterai dibawah $11,1 \mathrm{~V}$, makan aplikasi akan menampilkan status LOW dan ketika tegangan di atas 13,9 V maka aplikasi akan menampilkan status HIGH.

\subsubsection{Sistem Pengawas Wiring Trip Coil}

Sistem ini bertugas untuk mengawasi Rangkaian kabel dan kondisi trip coil. Jika sistem tersebut dalam kondisi normal, maka rangkaian terhubung dan ujung rangkaian akan mendapatkan tegangan negatif. Tegangan negatif tersebut kemudian digunakan sebagai acuan oleh optocoupler..

Tabel 10. Hasil pengujian output optocoupler

\begin{tabular}{ccc}
\hline $\begin{array}{c}\text { Kondisi } \\
\text { Rangkaian }\end{array}$ & $\begin{array}{c}\text { Nilai Output } \\
\text { Optocoupler }\end{array}$ & $\begin{array}{c}\text { Status Pada } \\
\text { Aplikasi }\end{array}$ \\
\hline Terhubung & $5 \mathrm{~V}$ & Normal \\
\hline Terputus & $0 \mathrm{~V}$ & Failure \\
\hline
\end{tabular}

Dari dat yang telah diperoleh di atas, dapat dilihat bahwa optocoupler dapat bekerja dengan bail. Jika terdapat tegangan negatif pada kaki input optocoupler, maka output dari optocoupler akan bernilai HIGH (5V). Jika rangkaian wiring trip coil terdapat kerusakan/terputus, maka kaki input dari optocoupler tidak mendapatkan tegangan negatif, sehingga output optocoupler akan bernilai LOW (0V) 


\subsubsection{Aplikasi Interface Pada Ponsel Android}

Pada pengujian aplikasi ponsel Android, data yang ditampilkan telah sesuai dengan nilai realtime database dan nilai yang terukur pada Arduino.

\begin{tabular}{|c|c|c|c|}
\hline \multicolumn{4}{|r|}{ 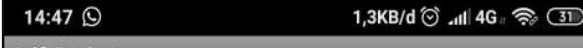 } \\
\hline \multicolumn{4}{|l|}{ Arif-Project } \\
\hline \multicolumn{4}{|c|}{$\begin{array}{c}\text { MONITORING SISTEM } \\
\text { PROTEKSI }\end{array}$} \\
\hline \multicolumn{4}{|c|}{ GARDU BLIMBING } \\
\hline \multicolumn{4}{|c|}{ Tegangan } \\
\hline Baterai & & NORMAL & $12.23 \mathrm{~V}$ \\
\hline Power Supp & & NORMAL & $12.61 \mathrm{~V}$ \\
\hline \multicolumn{4}{|c|}{ WIRING TRIP COIL } \\
\hline Kampus 1 & & NORMAL & TERHUBUNG \\
\hline Kampus 2 & & NORMAL & TERHUBUNG \\
\hline Kampus 3 & & NORMAL & TERHUBUNG \\
\hline \multicolumn{4}{|c|}{ Riwayat Anomali } \\
\hline \multicolumn{4}{|c|}{ 2019/7/19 14:47:1 (Batt_LOW=10.23V) } \\
\hline $2019 / 7 / 19$ & \multicolumn{3}{|c|}{ 14:47:11 (Supply_HIGH=15.61V) } \\
\hline 2019/7/19 & \multicolumn{3}{|c|}{ 14:46:40 Kampus_2 (Trip Coil_Failure) } \\
\hline 2019/7/19 & $14: 46: 51$ & Kampus & I (Trip Coil_Failure) \\
\hline
\end{tabular}

Gambar 6. Tampilan Aplikasi Pada Ponsel Android

Dari data di atas dapat dilihat bahwa aplikasi telah berjalan sesuai dengan program yang telah dirancang sebelumnya. Terdapat selisih waktu sebesar $1-5$ detik ketika terdapat perubahan nilai pada Arduino hingga data diterima dan ditampilkan oleh aplikasi Android. Selisih waktu ini bervariasi menyesuaikan kecepatan akses internet pada saat itu.

\section{KESIMPULAN}

\subsection{Kesimpulan}

Dari hasil pengujian yang telah dilaksanakan dalam tugas akhir ini, dapat disimpulkan sebagai berikut:

a. Tegangan input catu daya sebesar $223 \mathrm{~V}$ dan tegangan output catu daya sebesar $12.50 \mathrm{~V}$ telah sesuai dengan spesifikasi yang tertera.

b. Kondisi baterai sebagai catu daya cadangan dalam keadaan $98 \%$ dengan tegangan sebesar $12,47 \mathrm{~V}$ telah sesuai dengan spesifikasi.

c. Tegangan Arduino pada pin $5 \mathrm{~V}$ bernilai $4,98 \mathrm{~V}$ dan pin 3,3 V bernilai $3.325 \mathrm{~V}$ telah sesuai dengan spesifikasi alat. Toleransi tegangan arduino yaitu sebesar $\pm 5 \%$ dari nilai tegangan tersebut.

d. Terdapat selisih antara nilai analog yang terbaca pada arduino dengan perhitungan. Hal ini dikarenakan peralatan yang digunakan untuk mengukur memiliki tingkat akurasi yang berbeda-beda. Perbedaan ini dapat ditoleransi dengan cara mengkalibrasi hasil pengukuran tersebut dalam program yang akan dibuat.

e. Pembacaan digital input pada arduino telah sesuai dengan spesifikasi alat tersebut yaitu bernilai 1 dan 0 . 
f. Trafo CT mengeluarkan tengangan sebesar $43.2 \mathrm{mV}$. Output CT telah sesuai dengan spesifikasi alat yaitu Vout sebesar $16 \mathrm{mV} / 1$ Ampere.

g. Kontaktor bekerja dengan baik karena dapat menghubungkan dan memutuskan rangkaian listrik sesuai dengan spesifikasi alat tersebut.

h. Wifi shield dapat menghubungkan perangkat arduino dengan jaringan internet sesuai dengan spesifikasi alat tersebut.

i. Terdapat selisih waktu sebesar 0.2035 detik antara waktu tunda perhitungan dengan waktu tunda yang diperoleh dalam pengujian alat. Hal ini disebabkan karena terdapat proses pergerakan mekanik yang membutuhkan waktu kerja berbeda-beda pada masing-masing peralatan.

j. Terdapat delay pengiriman data selama 5 detik pada arduino disebabkan karena kecepatan trafik data internet yang dapat berubah-ubah setiap waktu.

k. Hasil pengujian alat menunjukkan bahwa rancang bangun prototipe monitoring sistem proteksi OCR elektronik secara wireless dapat berfungsi dengan baik. Hal ini ditunjukkan dengan hasil simulasi ketika terjadi gangguan pada sistem proteksi, alat ini mampu memberikan informasi gangguan tersebut kepada pengguna.

\subsection{Saran}

Pada perancangan tugaas akhir ini, penulis memberikan beberapa saran yang dapat digunakan untuk pengembangan dan perbaikan alat sesuai dengan kebutuhan dan perubahan teknologi:

a. Dapat diterapkan pada sistem kelistrikan yang lebih luas agar dapat mencegah kegagalan sistem proteksi, sehingga meningkatkan kualitas penyaluran energi listrik menjadi semakin baik.

b. Jika penggunaan alat dalam sistem yang lebih besar dan membutuhkan lebih banyak port input, dapat menggunakan mikrokontroler yang memiliki kapasitas lebih besar

\section{DAFTAR PUSTAKA}

[1] H. J. Lingal and O. S. Jennings, "Circuit Breaker Protection for Industrial Circuits," Transactions of the American Institute of Electrical Engineers, vol. 52, no. 2, pp. 568-576, Jun. 1993.

[2] M. Pornomo, "Monitoring Pengawatan Tripping Coil dan Suhu Kontak PMT untuk Mengantisipasi Kegagalan Trip," Skripsi, UNIVERSITAS 17 AGUSTUS 1945, Surabaya, 2016.

[3] Yokins, "Yokins CT, Industrial \& Scientific," 2017. [Online]. Available: https://www.amazon.in/Yokins-Current-Transformer-600A-Pack/dp/B013WZ9FOQ. [Accessed: 02Jul-2019].

[4] "Arduino - Introduction." [Online]. Available: https://www.arduino.cc/en/Guide/Introduction. [Accessed: 11-Nov-2017].

[5] M. IHSAN, "Analisis Dan Redesign Grid Plate Positive Dan Negative Lead-Acid Battery Dengan Simulasi Distribusi Elektron Yang Merata Untuk Meningkatkan Service Life Pada Lead-Acid Battery," Institut Teknoligi Sepuluh Nopember, Surabaya, 2017.

[6] A. Akhdan, "Rangkaian Interlock dengan Kontaktor magnet," Sains, Entertaining, and Technology, 16-Oct-2015. .

[7] S. Maniktala, Switching Power Supply Design and Optimization. McGraw-Hill, 2004.

[8] suprianto, "Pengertian Optocoupler dan Prinsip Kerjanya," All Of Life, 11-Oct-2015. [Online]. Available: $\quad \mathrm{http}: / / \mathrm{blog}$.unnes.ac.id/antosupri/pengertian-optocoupler-dan-prinsip-kerjanya/. [Accessed: 11-Jan-2018].

[9] "IEEE Recommended Practice for Protection and Coordination of Industrial and Commercial Power Systems (IEEE Buff Book)," IEEE Std 242-2001 (Revision of IEEE Std 242-1986) [IEEE Buff Book], pp. 1-710, Dec. 2001. 